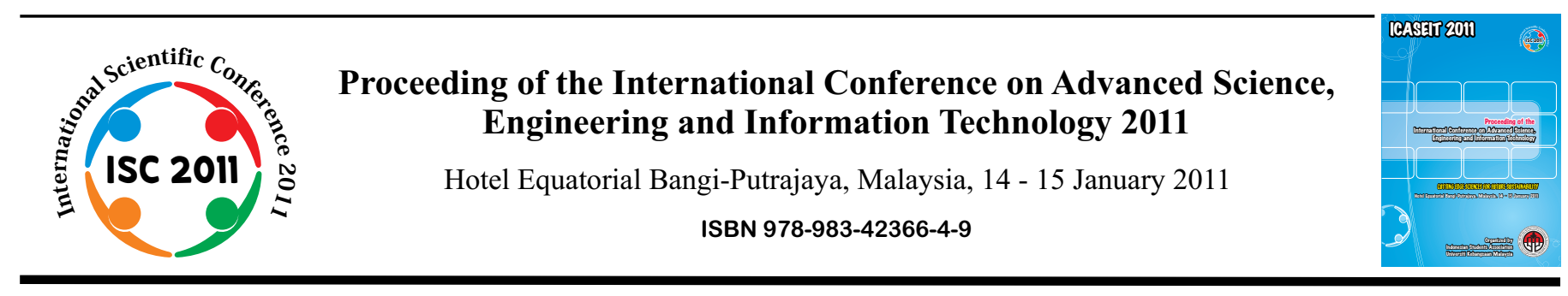

\title{
Real-Time Control of Wi-Fi Surveillance Robot
}

\author{
Poh Eng Fong, Mohd Amaluddin Yusoff \\ Department of Electrical and Computer Engineering, Curtin University \\ CDT 250, Miri, 98009, Sarawak, Malaysia \\ Tel.:+6085443939,E-mail: engfong.poh@gmail.com, amaluddin@curtin.edu.my
}

\begin{abstract}
This paper presents the design of a low cost Wi-Fi surveillance robot. The purpose of this surveillance robot is to navigate and deal with multiple-angled monitoring towards the environment with inexpensive hardware and free software cost. The desirable wireless standards used in this design is IEEE $802.11 \mathrm{~b} / \mathrm{g}$ (Wi-Fi) due to its range up to 152 meters with 54Mbps. Robot will be constructed in four wheels. Two driven wheels are needed to navigate the direction along with two caster wheels.
\end{abstract}

Keywords - Wi-Fi, Surveillance, Robot, Wireless Router.

\section{INTRODUCTION}

Currently there is a lot of intelligent Closed-Circuit Televisions (CCTV) available in the market. Those CCTV are often installed in the area where monitoring is needed. However, there is a lack of surveillance system with mobile robot that can be navigated and multiple-angle monitored the environment remotely. Furthermore, a lot of RF links are widely used in developing embedded system and the hardware cost is inexpensive, but with some limitations such as limited range, operation depending on base $\mathrm{PC}$, custom written communication protocol required, time consuming in developing and design[1]. The design presented in this paper addressed the problem stated above. There are two wireless standards widely used, IEEE 802.15(Bluetooth) and IEEE $802.11 \mathrm{~b} / \mathrm{g}$ (Wi-Fi). On one hand, low power consumption and cost are the significant advantages of Bluetooth Technology. However Bluetooth technology only has the range up to 10 meter, which is much favorable for connectivity between computer and cell phones, PDAs, camera and so on. On the other hand, 802.11 technologies will be the better option for this design, since it has the range up to 152 meters and the bit rate up to $54 \mathrm{Mbps}$ [3], which give us a hand to navigate the robot and monitor remotely. In addition, using the minimal cost to build the robot is one of the important objectives of this design. There are many methodologies to build and control a robot, however, it was found that a four wheeled mobile robot will be much simpler to construct with lower cost. The four wheeled mobile robot consisted two driven wheels which make the robot can be navigated in any direction and along with two caster wheels [4].

\section{SYSTEM OVERVIEW}

The main objectives of this design are to build a robot that can be navigated remotely and wirelessly monitor the environment in multiple-angle in minimal development cost. The user can control the robot through a computer which can access a Wi-Fi network and a Visual Basic application. The two methods how the user can access the robot are depicted in Fig.1. Fig.2 illustrates functional block diagram of the design. The details of each component will be discussed in next section.

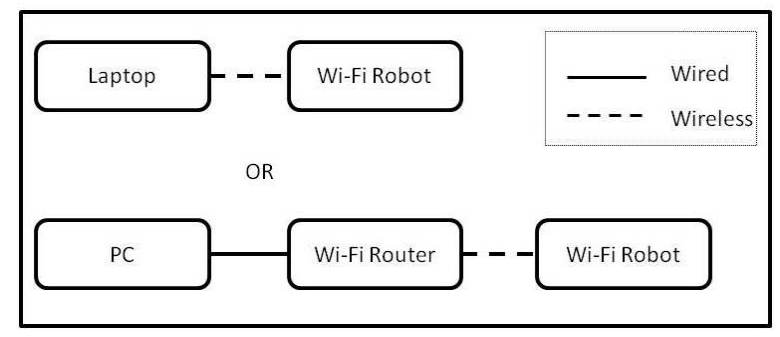

Fig. 1 Elementary block diagram of the design 


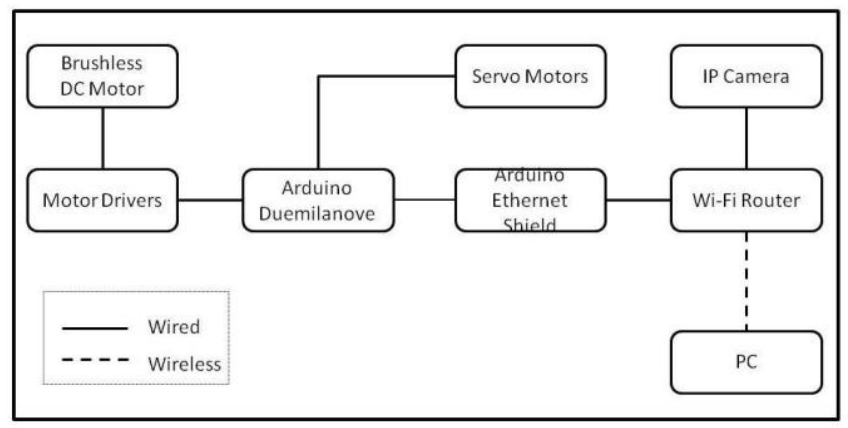

Fig.2 Functional Block Diagram of the Design

\section{HARDWARE DESIGN}

The hardware required in this design is listed in Tab. 1 and Fig. 3 shows how the actual hardware is integrated. Those important components like wireless router, microcontroller, motor and motor driver, and IP camera will be discussed in detailed in this section.

TABLE I

EQUIPMENT LIST

\begin{tabular}{|l|c|c|}
\hline \multicolumn{1}{|c|}{ Items } & Quantity & Weight $($ Kg $)$ \\
\hline Wi-Fi Router & 1 & 0.482 \\
\hline Arduino Duemilanove & 1 & 0.050 \\
\hline Arduino Ethernet Shield & 1 & 0.050 \\
\hline Motor Driver & 2 & 0.480 \\
\hline DC Motor & 2 & 3.200 \\
\hline Servo Motor & 3 & 0.070 \\
\hline IP Camera & 1 & 0.277 \\
\hline 12V Lead Acid Battery & 4 & 2.080 \\
\hline Squre Robot Chasis & 1 & 3.300 \\
\hline Tire & 2 & 0.640 \\
\hline
\end{tabular}

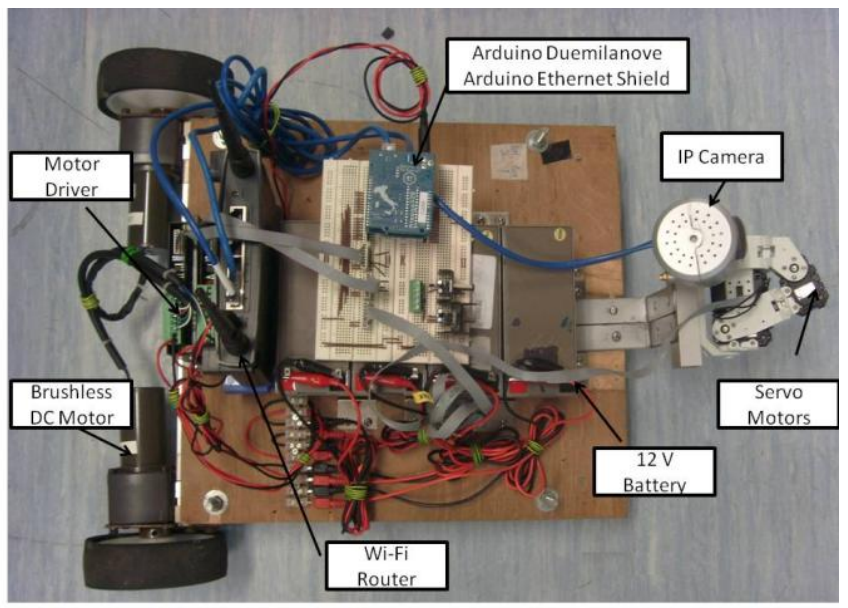

Fig. 3 Wi-Fi Surveillance Robot

\section{A. Wireless Router}

A router is a networking device which can interconnect two or more computer networks. This router powered up by $12 \mathrm{~V}$ battery. The user's computer will connect to this router's network and give command to the microcontroller. Besides that, the router was connected with an IP camera used in motoring purpose. The router we used in this design is Linksys Wireless-G Broadband Router WRT54GL, as showed in Fig.4, which is a well known router and developed under IEEE Standard 802.11. It can be used in this design with minimal configuration.

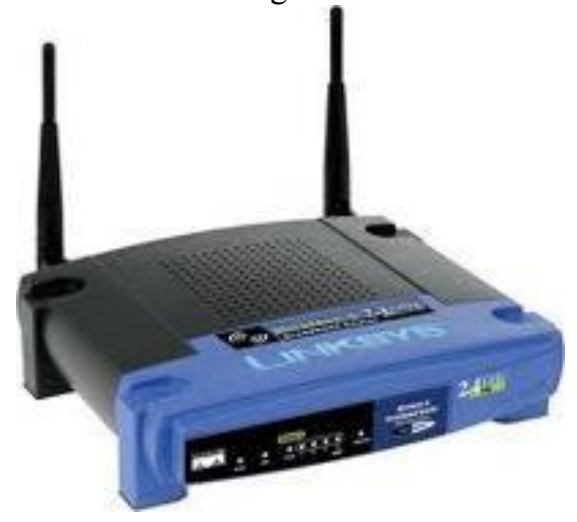

Fig.4 Linksys Wireless-G Broadband Router WRT54GL

\section{B. Arduino Duemilanove and Ethernet Shield}

The Arduino Duemilanove is an open source microcontroller with inexpensive cost compared to other microcontroller and supported by huge community. It can be powered via USB connection or external power, 6 analog input pins and 14 digital $\mathrm{I} / \mathrm{O}$ pins. Besides that, it has both open source extendable software and hardware. Arduino Ethernet Shield is one example of extendable hardware. The Arduino Duemilanove can connect to internet by mounting with the Arduino Ethernet Shield. The chip on the Ethernet Shield, Wiznet 5100, provided a network IP stack capable with UDP and TCP. This module will receive the commands from the user and give appropriate signal to the motor driver to control the robot movement and control tuning angle of servo motors which an IP camera is housed.

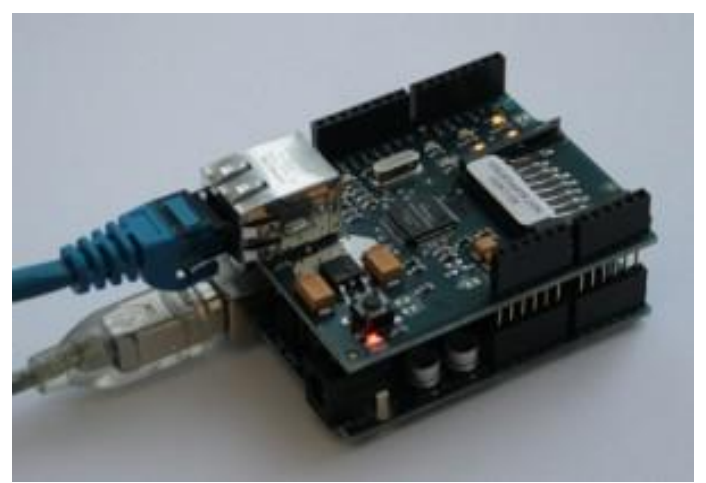

Fig.5 Arduino Duemilanove and Ethernet Shield 


\section{Brushless DC Motor and Driver}

The motor driver is operating at DC $24 \mathrm{~V}$. The motor driver is connected to the microcontroller which will control the speed by PWM signal.

TABLE II

TRUTH TABLE OF MOTOR DRIVER

\begin{tabular}{|c|c|c|c|c|}
\hline \multicolumn{2}{|c|}{ Left Motor } & \multicolumn{2}{c|}{ Right Motor } & $\begin{array}{c}\text { Robot } \\
\text { Behaviour }\end{array}$ \\
\hline Run/Brake & CW/CCW & Run/Brake & CW/CCW & IDLE \\
\hline 1 & X & 0 & X & $\begin{array}{c}\text { Moving } \\
\text { Backward }\end{array}$ \\
\hline 1 & 0 & 1 & 0 & $\begin{array}{c}\text { Turing } \\
\text { Left }\end{array}$ \\
\hline 1 & 1 & 1 & 0 & $\begin{array}{c}\text { Turning } \\
\text { Right }\end{array}$ \\
\hline 1 & 1 & 1 & 1 & $\begin{array}{c}\text { Moving } \\
\text { Forward }\end{array}$ \\
\hline
\end{tabular}

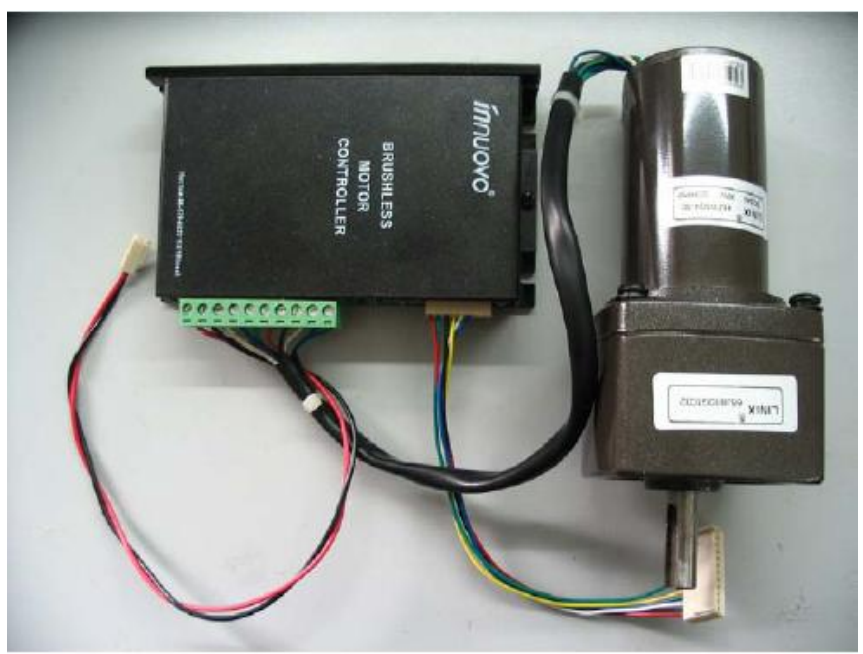

Fig.6 Brushless DC Motor Driver

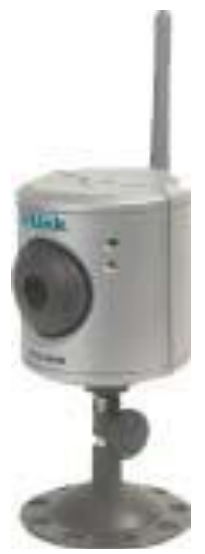

Fig. 7 IP Camera DCS-900W

\section{IP Camera}

The IP camera in this design must be able to be standalone, CPU and Web server built-in, and can be integrated with Ethernet network. DCS-900W fulfils the requirements stated above.

\section{E. Servo Motor}

The Servo motors are connected to microcontroller to adjust the viewing angle of IP camera for better monitoring purpose. It was driven by Pulse Width Modulation (PWM) signal from the microcontroller.

\section{SOFTWARE DESIGN}

The software design can be categorized into two parts: embedded web server for microcontroller and user control application.

\section{A. Embedded Web Server}

The Arduino software was published as open source tool which can run on cross-platform such as Window, Macintosh OSX, and Linux Operating System. This Arduino Integrated Development Environment is written in Java. It is very easy for the programmer to write the $\mathrm{C}$ code and upload it to the microcontroller

After the web server code is uploaded to the microcontroller which is connected to the router, the user in the same network can access this server through any Internet browser like Internet Explorer or Mozilla Firefox and control the robot to move but without any image or video from the IP camera. The text, button shows in the web browser is written in HTML format.

However, there is some limitation for the embedded web server such as memory, processing speed and response. Therefore, it is not suitable to implement too complicated webpage on the web server.

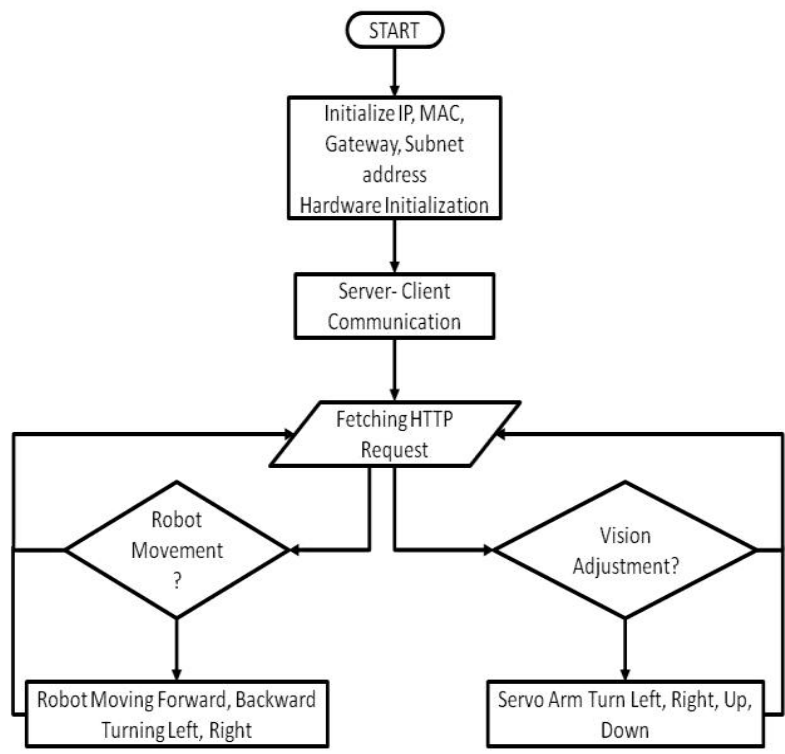

Fig. 8 Flow Chart of Embedded Web Server 


\section{B. User Control Application}

The User Control Application is developed under Microsoft Visual Basic 2010 Express, which can be freely downloaded from Microsoft official website.

The User Control Application is a PC-based application which will send the HTTP request to the microcontroller in order to control the robot movement and the IP camera. This application is written in three modules as showed in Fig.9 and each module work independently. The "Robot Movement" and "Camera's Vision Adjustment" modules are in charge of sending commands to microcontroller. The "Video Streaming \& Image Storing" shows the video signal from the IP camera, captures the particular screen, converts and stores as a JPEG file. Thus, the PC should allocate some free disk space for capturing large amount of picture. Fig.9 shows how the User Control Application associates with the Embedded Web Server in the microcontroller and the IP camera.

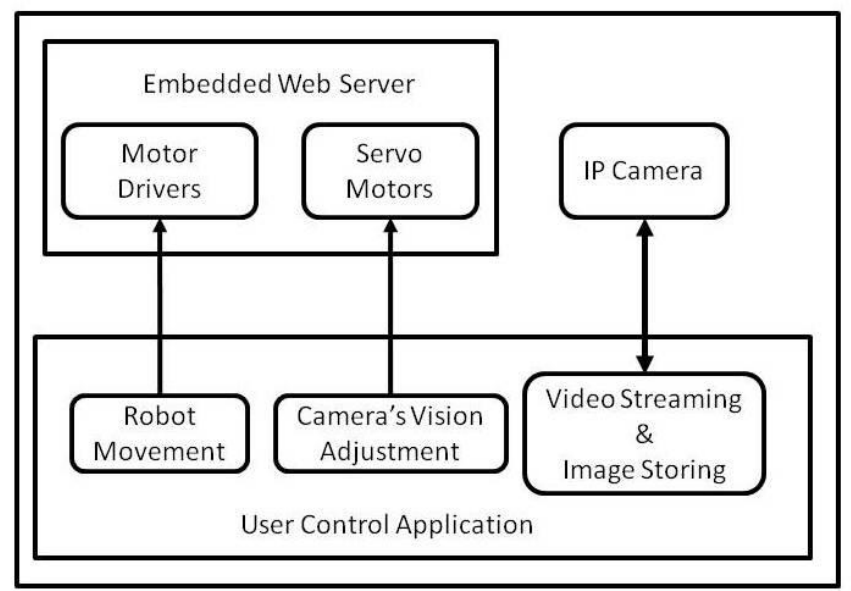

Fig. 9 Association of Embedded Web Server and User Control Application

\section{EXPERIMENT RESULT}

The experiment is using the IEEE 802.11 Wi-Fi standard connection between the remote PC and the robot. The robot can be controlled and take picture by remote user. The experiment is carried in both indoor and outdoor. Fig.9 showed that the robot can be navigated remotely and capture video signal from the IP camera. In order to achieve satisfactory result in both cases, an extra cooling system is needed when the robot is navigating in an outdoor environment.

\section{RECOMMENDATION AND FUTURE WORK}

There are two methodologies to improve the performance of this Wi-Fi surveillance robot. Firstly, a Global Positioning system can be installed into the system. The future developer can program the robot to patrol several check points from time to time automatically. The increase of patrols will enhance the performance of monitoring. Secondly, a selfcharging system and batteries monitoring system can be included into to the design. Since the robot is able to carry out patrols frequently and the lead acid batteries are rechargeable, it can be programmed to find the nearest char-

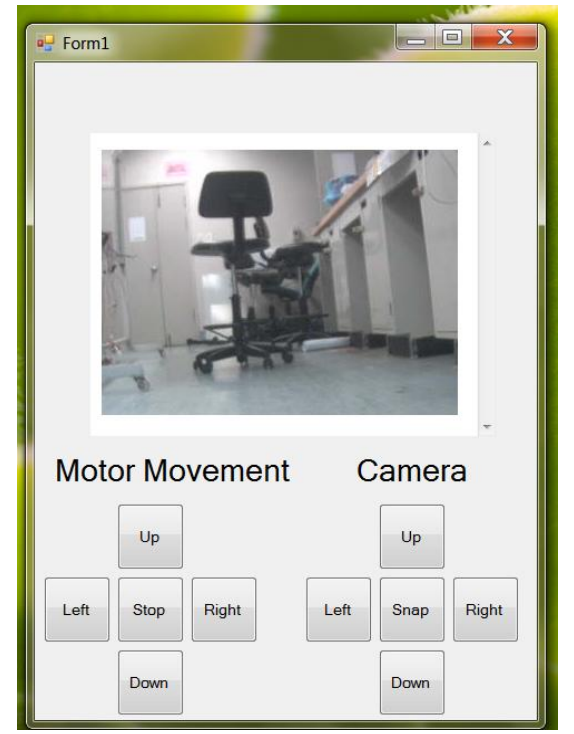

Fig. 10 User Control Application's screen shot

ging point to charge up itself. The patrol mission will be able to carry out immediately after is done.

Besides that, since the IEEE 802.11 technology is widely used nowadays, this robot just needs to add appropriate hardware so that it can be applied in the following fields:

- Medical care monitoring

- Industrial processes

- Hazard or vacuum environment

- Boom disposal

- Exploration Robot

\section{CONCLUSION}

This paper describes the hardware and software design of Wi-Fi Surveillance Robot. The Arduino Duemilanove and Arduino Ethernet Shield is the microcontroller that connects to a Wi-Fi router. The mobile robot can be control remotely through a PC base User Control Application and monitor the environment through an IP camera. The experiment is successfully done with navigating and monitoring in an indoor environment by a remote user.

\section{REFERENCES}

[1] G. Sen Gupta, S. C. Mukhopadhyay and J. R. French, "Wireless Communications and Control Module of a WebEnabled Robot for Distributed Sensing Application", in Instrumentation and Measurement Technology Conference Proceedings, 2008, paper10.1109, p.393-398.

[2] Christopher G. Wilson and Thaddeus Roppel, "Low-cost Wireless Mobile Ad-Hoc Network Robotic Testbed", in Testbeds and Research Infrastructures for the Development of Networks \& Communities and Workshops, 2009, p.1-6.

[3] Asma Bait Fadhah, Athra' Al-Lawati, Sara Al-Maskari, Abderezak Touzene and Ahmed Al-Kindi, "Experiment Performance Evaluation of Wireless 802.11b Networks", in Applications of Digital Information and Web Technologies,2008,p. 151-155.

[4] Carlos Cardei and Jose Sa da Costa, "A Low Cost Mobile Robot for Engineering Education”, in Industrial Electronics Society, 2005, p. 16. 